\title{
What do UK doctors-in-training value in a post? A discrete choice experiment
}

Jennifer Cleland ${ }^{1}$, Peter Johnston², Verity Watson ${ }^{3}$, Nicolas Krucien³ Diane Skåtun ${ }^{3}$

${ }^{1}$ John Simpson Chair of Medical Education, Division of Medical and Dental Education (DMDE), School of Medicine and Dentistry, University of Aberdeen, Aberdeen, Foresterhill, AB25 2ZD

${ }^{2}$ Associate Postgraduate Dean, NHS Education for Scotland, Northern Deanery, Foresterhill, Aberdeen, AB25 2ZP

${ }^{3}$ Senior Research Fellow, Research Fellow and Senior Research Fellow respectively, Health Economics Research Unit (HERU), School of Medicine and Dentistry, University of Aberdeen, Foresterhill, Aberdeen, AB25 2ZD

Corresponding author:

Professor Jennifer Cleland

John Simpson Chair of Medical Education

School of Medicine and Dentistry

University of Aberdeen

Foresterhill

Aberdeen

AB25 2ZD

Tel: 01224437257

Email: jen.cleland@abdn.ac.uk 


\section{Abstract}

\section{Introduction}

Many individual- and job-related factors are known to influence medical careers decision making. Medical trainees' (residents) views of which characteristics of a training post are important to them have been extensively studied but how they trade off these characteristics is under-researched. Such information is crucial for the development of effective policies to enhance recruitment and retention. Our aim was to investigate the strength of UK foundation doctors and trainees' preferences for training post characteristics in terms of monetary value.

\section{Methods}

We used an online questionnaire study incorporating a discrete choice experiment (DCE), distributed to Foundation Programme doctors and doctors in training across all specialty groups across three UK regions, in August-October 2013. The main outcome measures were monetary values for trainingpost characteristics, based on willingness to forgo and willingness to accept extra income for a change in each job characteristic, calculated from regression coefficients.

\section{Results}

1323 trainees answered the questionnaire. Good working conditions were the most influential characteristics of a training position. Trainee doctors would need to be compensated by an additional $49.8 \%$ above the average earnings within their specialty to move from a post with good working conditions to one with poor working conditions. A training post with limited rather than good opportunities for one's spouse/partner would require compensation of $38.4 \%$ above the average earnings within their specialty. Trainees would require compensation of $30.8 \%$ above the average earnings within their specialty to move from a desirable to a less desirable locality. These preferences varied only to a limited extent according to individual characteristics.

\section{Discussion}

Trainees place most value on good working conditions, good opportunities for their partner and desirable geographical location when making careers-related decisions. This intelligence can be used to develop alternative models of workforce planning and/or to develop information about job opportunities which address trainees' values.

300 words 


\section{$\underline{\text { Introduction }}$}

Medical education and training systems in most countries allows doctors in training considerable individual choice about which speciality they select and where they wish to train. This flexibility is desirable to the doctor in training, but not necessarily for the country's health service: for example, in the UK, there is a well-publicised crisis caused by the inability to recruit doctors into training (resident) posts in several specialties and in geographically-peripheral areas of the UK. These difficulties are illustrated, for example, by the $89.3 \%$ fill rate across all specialties for training posts in England in the 2013 recruitment round (for taking up post in August 2014) and by training posts in urban centres being more popular than those in the periphery and/or rural locations throughout the UK (1-3). There are also problems retaining trainees throughout the training pathway until they acquire evidence of training completion and progress to fill consultant vacancies (e.g. 4-5).

These examples illustrate a growing gap between demand and supply in the medical workforce - or NOT having the right people with the right skills, in the right place, at the right time. The reasons for this are multiple. Trends such as the increasing numbers of women in the profession (e.g., 6-9) and the growing popularity of work-life balance (e.g., 10-13), including part-time training and working (e.g., 14) are relevant. If the numbers of doctors being educated and trained stays the same but those doctors wish to train and work less than full time, the "numbers needed to treat (patients)" will be insufficient, impacting on the reliable delivery of care now, and in the future.

How are those who commission medical education responding to supply-demand issues? Rather than increasing the number of doctors educated and trained, diverse governments have/are seeking new models of care driven by service needs not professions. Many traditional doctors' roles are now seen as deliverable by other healthcare professionals (e.g., 15, 16). This direction of travel involves scrutiny of the unique skills and contribution of a doctor and has the potential to change the face of medical practice, and hence education and training, perhaps in ways considered undesirable to medical educators and doctors.

Rather than leaving decisions about medical education and training, and the role of doctors in a health service, to those whose focus is meeting healthcare demand by whatever means possible, medical educators must connect explicitly with policy makers and education commissioners in order to inform and influence solutions to current and anticipated future shortages of doctors. To do so depends on relevant analyses of medical careers preferences. This is not a new field of research: as 
mentioned earlier, studies have identified influencing factors and preferences such as gender (e.g., 6-9) wish for work/life balance (e.g., 10-14), as well as individual preferences $(17,18)$ and the importance of prior experience/exposure to a specialty (e.g., 19, 20). However, it is an area of research which has been over-dominated by one research method: the descriptive survey $(6-14,17-$ 28). This approach can identify preferences but that is only the start of knowledge building: it is also crucial to identify the relative strength, or value, of careers preferences $(29,30)$.

To achieve this, we engaged in inter-disciplinary research (31) with health economist colleagues, to draw on the theories, insights and methods from this discipline to investigate medical careers preferences. Together, we developed and carried out a discrete choice experiment, a quantitative design which is commonly used to study the labour market preferences of health workers (e.g., 32) but, as yet, has been used infrequently to study medical work-related preferences in developed countries (33-35). Indeed, to the best of our knowledge, there have been no previous studies examining generic "push-pull" factors in medical careers decision making (36). A push factor is a force which drives people away from a place (e.g., lack of career opportunities) and a pull factor is what draws them to a new location (e.g., availability of careers opportunities).

Our specific aim in using this approach was to examine the most important "push-pull" factors in UK trainee doctor career decision making, a group whose preferences are arguably the most important for the future of the medical workforce. 


\section{Methods}

\section{Context}

This study was carried out in the UK. To help the reader, Figure 1 provides an overview of the basic structure of the UK medical education and training pathway. There is a common stem of training medical school and Foundation Programme training, a two-year broad-based training programme which follows graduation from medical school. Successful completion of the FP is an eligibility criterion for applying to specialty training, including general practice [family medicine]. The precise organisation of training after the FP depends on the specialty: general practice (GPVTS: equivalent to family medicine) is currently a three year programme. Other training programmes may be runthrough (which means one point of career decision making, at the end of the FP, then 5-8 years of post-FP training) or sub-organised into core and higher specialty training (where the doctor has to apply for core and higher specialty training separately, and in total completes 7-8 years of training). The awards of CCT (Certificate of Completion of Training) or CESR (Certificate of Eligibility for Specialist Registration) are required to work as a consultant.

\section{Figure 1: Overview of the UK medical education and training pathway}

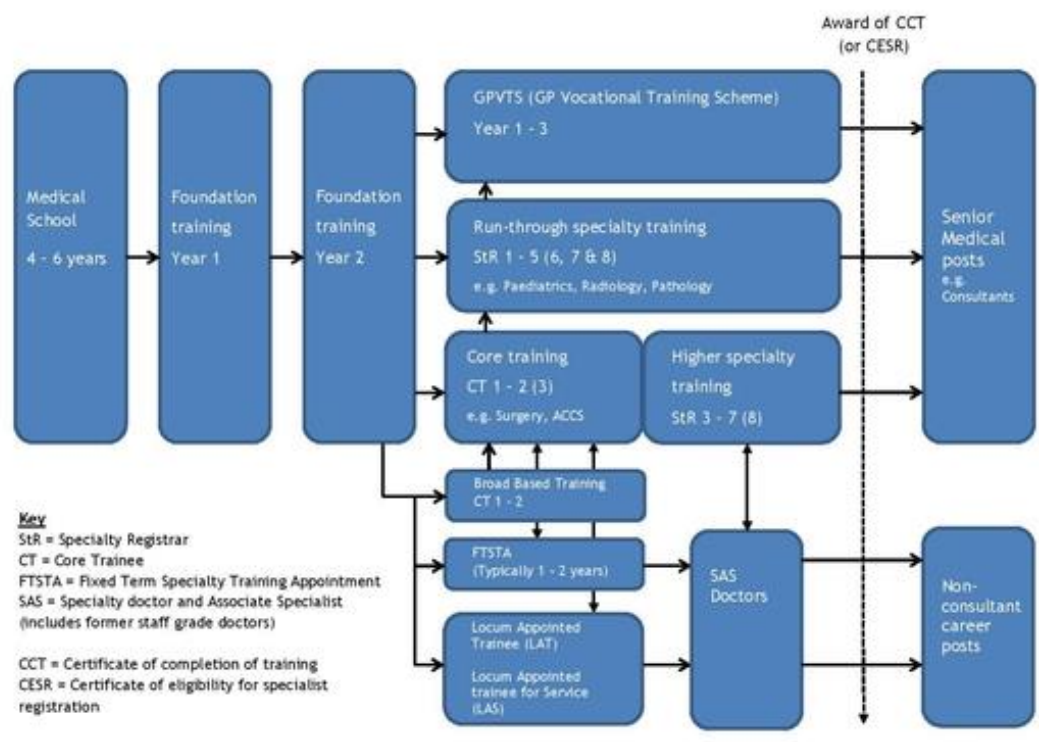

\section{Discrete choice experiment}

A DCE is a quantitative technique for eliciting preferences for multi-attributes goods, commonly used in health economics for addressing a wide range of policy questions (37). A DCE involves asking individuals to state their preference over hypothetical alternatives, in this case training posts. Each 
alternative is described by several characteristics (e.g., income, reputation of post's location) the levels of which vary over alternatives (e.g., higher income, worse reputation). The observed choices are used to determine individuals' preferences for changes in the characteristics.

In indicating a preference for one alternative over another, the individuals are trading-off the different bundles of characteristics that make up the competing alternatives. The bundling together of characteristics mimics real life where a good, service or in this case a training position is not made up of any one characteristic but a whole set within which individuals must trade-off the position's strengths and weaknesses. The choice made by the individual between these competing bundles of characteristics allows the influence of the underlying characteristics on individuals' decisions to be estimated. Since choice responses provide information on how individuals' trade-off one attribute for another, a monetary attribute is typically included in a DCE. This allows the model to estimate a willingness to pay/accept measure, that is, how much money individuals are willing to trade or willing-to-pay (WTP) for improvements in other attributes within the bundle or how much they are willing-to-accept (WTA) for a deterioration in other attributes. The willingness to pay/accept measures place all characteristics on a common metric and aids the comparison of impact of each characteristic on individuals' training position choice.

DCEs are increasingly used in studies of the labour-market choices of healthcare professionals (3234). To the best of our knowledge, however, the only study using this method with trainee doctors focused on why Australian trainees do not want to become general practitioners (35). In contrast, the current study is designed to be independent of specialty choice.

\section{Development of attributes and levels}

In this DCE survey respondents are asked to make a series of choices between hypothetical training positions. Each training position is defined by a set of attributes reflecting training post characteristics. Following best practice in designing DCEs (38), we used qualitative methods to ensure that the attributes and levels in the DCE were clear, sensible, meaningful and allowed respondents to make realistic trade-offs between them. This involved a two-step process. First, we consulted international literature on medical labour markets and careers decision making to identify which attributes might be relevant. Second, little of the literature was drawn directly from the population we wished to study, therefore to bridge this evidence gap and to refine the choice of attributes further from the factors we identified in the literature, we also administered an online qualitative survey of doctors in training (Foundation Programme and early years of Core or Specialty 
Training) in four Scottish and one English region. We asked for the top three factors which had influenced their decision making, and asked them to provide a short explanation of why these factors were important. The online survey was anonymous, distributed by the postgraduate training bodies in those regions and live for one month. The survey responses were analysed using a thematic approach to identify recurring themes (39), which is reported elsewhere (40)

This two-step methodology identified five characteristics of training positions that were likely to be major drivers of post-graduate trainee doctors in their medical careers decision-making behaviour. Different levels or realisations must be attached to each of the characteristics included in the DCE. These levels need to be plausible descriptions of the characteristics. The levels included in the DCE were informed by the existing literature, the qualitative survey (see above), the expert knowledge of the research team, and were pre-piloted with a small group of trainees who gave feedback about the range and wording of the attributes and levels.

Table 1 shows the final attributes and their possible levels. Note that while earnings was not identified in the qualitative survey as a main motivator for our respondents, a DCE uses an earnings characteristic to compute the WTP/A, and to measure preferences for attributes' levels on a same dimension (e.g. money), allowing thus for direct comparison of estimates between characteristics.

\section{Table 1 about here}

In this study, the training positions were presented in choice sets containing two hypothetical positions. Respondents were asked to state which position they would prefer. Respondents were not offered an opt-out (no training position) alternative. This reflects our primary interest in the factors affecting choice of training locations as opposed to factors influencing the decision to leave the profession entirely. Before the DCE questions were presented, the task that respondents would be asked to complete was explained and a detailed description of each characteristic and its corresponding levels was presented. Full instructions and an example choice scenario are provided in Figure 1.

\section{Figure 1 about here}

\section{Experimental design}

Based on the characteristics and levels presented in Table 1 there are a total of 432 different possible training positions $\left(3^{3} \times 2^{2} \times 4^{1}: 3\right.$ characteristics with 3 levels and two characteristics with 2 
levels and one characteristic with four levels) with 93,096 possible choice sets(432*431/2) (41). . We used the software package SAS v9.3 (50) to reduce our design to 18 choice sets. The 18 choice sets were designed to allow for investigation of main (direct) effects of changes in the training position's characteristics on respondents' choices. The respondent burden was further reduced by allocating the 18 choices to two subsets with 9 choices. From the two sets of 9 choices, we developed two questionnaires, which were identical apart from the particular DCE choice sets respondents were asked to complete.

\section{Sample and Data Collection}

The questionnaires were distributed to all trainee doctors in Scotland and the North of England (The Scotland Deanery, Health Education North East and Health Education North West) in August 2013. This gave an approximate population of 16,700 doctors in training in total, split roughly into 10,850 in the North of England, 5,850 in Scotland.

Survey links were distributed by the postgraduate training providers taking part in this study. The survey was live for 25 days with reminders sent out in the middle of this time period. Respondents were automatically randomly allocated to one of the two survey versions. Consent was assumed by questionnaire completion. No identifying details were sought from respondents. Respondents could voluntarily include their name and contact email if they wished to be considered for a prize draw for an iPad. Otherwise, at no time did the project team have access to personal details of the target group of respondents.

\section{Econometric estimation}

Choice data are analysed with discrete choice models based on the Random Utility Maximisation (RUM) framework (42). RUM assumes that respondents choose the most desirable training position given their preferences for the position's characteristics. However it recognises that this choice is partly random either because the analyst does not fully observe all determinants of the respondent's choices or the respondents make some mistakes in their decisions. This means that the choices are explained in two parts: an observable (systematic) part and an unobservable (random) part. The unobserved part of the utility is represented by an error term. As is common practice in the choice modelling literature, we use a standard conditional Logit model to analyse the individuals' choices (see equation 1 ) where the error term is assumed to be independently and identically distributed (IID) as a Gumbel variable. Given that each respondent answered nine choice tasks, these 
error terms were likely to be correlated within individuals and use cluster robust standard errors $(\text { CRSE })^{1}$.

$$
\operatorname{Pr}(j)=\frac{\exp \left(V_{j}\right)}{\sum_{k=1}^{K} \exp \left(V_{k}\right)}
$$

Where $\left(V_{j}\right)$ is the observed part of the utility procured by the characteristics of the training position. In this case:

$V_{j}=\beta_{0}+\beta_{1}$ Location: Desirable $+\beta_{2}$ Opportunities: Good $+\beta_{3}$ Reputation: Indifferent + $\beta_{4}$ Reputation: Excellent $+\beta_{5}$ Conditions: Poor $+\beta_{6}$ Conditions: Excellent + $\beta_{7}$ Familiarity: Unfamiliar $+\beta_{8}$ Familiarity:Very $+\beta_{9}$ Earnings

The coefficients $\left(\beta_{1}\right)$ to $\left(\beta_{8}\right)$ are interpreted as preferences and refer to the effects of qualitative characteristics on the individuals' choices: Geographic location; Opportunities for partner/spouse; Clinical/academic reputation; Working conditions; Familiarity. These effects are estimated using effects-coded variables a standard alternative approach to the use of dummy variables when analysing categorical variables. The parameter $\left(\beta_{9}\right)$ represents the effect of a $1 \%$ increase of the potential earnings compared to average career earnings in respondents chosen specialty. The constant term $\left(\beta_{0}\right)$ represents the utility of being training position $A$ compared to $B$ after having accounted for the effects of all characteristics ${ }^{2}$. These parameters convey two important results about respondents' preferences for characteristics of training positions. First the sign of the estimates (either positive or negative) indicates how an improvement in the characteristic will influence the trainees' decisions. In this study we expected improvements in all characteristics to have a positive effect on respondents' choices that is to increase the desirability of training positions. Second the magnitude of the estimates gives an indication of the (marginal) importance of the characteristic in trainees' decision making process. The further away from zero the more the characteristic contributes to the desirability of the training position. However one needs to keep in mind the unit of measurement of the characteristic when interpreting its effect. For a categorical characteristic, such as "Geographic location", the preference parameter will capture the effect of discrete change when moving from one state (i.e., undesirable) to another (i.e., desirable). For a quantitative characteristic, such as "Earnings", the preference parameter will measure the effect of a

\footnotetext{
${ }^{1}$ Initially we accounted for data clustering by using an error component structure for the discrete choice model but this showed no significant improvement over the standard conditional logit model.

${ }^{2}$ Because the training positions are unlabelled (i.e. A vs B), this effect should not be significant. However in DCEs this term is usually found significant because of an order effect known as left-to-right (reading) bias.
} 
marginal (continuous) change when increasing the earning level by 1 unit $(+1 \%)$. In this setting respondents' WTP/A for improvement/deterioration in the characteristics of the training positions can be simply computed as the ratio of 2 estimated preferences, the characteristic of interest $\left(\beta_{1}: \beta_{8}\right)$ and the earning attribute $\left(\beta_{9}\right)^{3}$. The WTP/A values provides a common comparison between attributes along with an actual monetary value in terms of the percentage loss or gain of potential earnings required in order to achieve an improvement or accept a deterioration in the respective attribute. Confidence intervals for the WTP/A values are calculated using a bootstrapping procedure with 10,000 replicates

It is reasonable to expect that preferences for training positions may be influenced by respondents' personal characteristics and their career stage, therefore we explored how the following personal characteristics affected respondents' preferences for training position characteristics:

- $\quad$ Current deanery (organised into Scotland and England for anonymous reporting purposes);

- $\quad$ Age (Younger than 30 years, Older than 30 years);

- $\quad$ Gender;

- $\quad$ Place of birth (Scottish, Rest of UK, Overseas);

- $\quad$ Relationship status (Single, Long-term relationship)

- $\quad$ Current training grade (Foundation years (FY), Core or Specialty training years 1 and 2 on a run through pathway (CTST/Y) or on an uncoupled training pathway (CTST/N), and Higher level specialty training levels 3 to 8 (ST)

- $\quad$ Desire to change deanery at next career decision-making point (Yes, No)

In discrete choice modelling, the heterogeneity of preferences due to differences in individual characteristics can be investigated using interaction terms between those characteristics and the individuals' preferences. The statistical significance of the interaction term indicates a systematic effect of the individual characteristic on the preferences. The challenge of specifying interaction effects between individuals' characteristics and preferences is the proliferation of parameters to be estimated in the choice model. In this study, there are 10 parameters associated with the respondents' preferences and the individuals' characteristics can be described using 9 parameters. A model specifying all possible interaction effects would include 100 parameters, making thus the model more difficult to interpret and increasing the risk of over-fitting. In this study, a variable selection procedure has been used to select a subset of meaningful interaction terms in the final

\footnotetext{
${ }^{3}$ This approach is based on the implicit assumption of linearity in preferences for the income attribute. In a preliminary analysis we formally tested this assumption, which appeared to be supported in our study.
} 
model. The selection procedure was based on LASSO (Least Absolute Shrinkage and Selection Operator) approach. In contrast to classical variable selection procedures, such as stepwise (forward/backward) selection, the LASSO approach guarantees a continuous, stable and computationally efficient variable selection (43). 


\section{Results}

\section{Respondents}

The questionnaire was answered by 1323 medical trainees of the 16700 trainee doctors in Scotland and the Deaneries within the North of England representing a response rate of $8 \%$ (1323/16700). The responses were grouped into Scotland $(n=743 ; 56.1 \%)$ and England $(n=530 ; 42.1 \%)$ with 50 (3.8\%) non-attributable responses not entered into the analysis. Females comprised $67 \%$ of the sample with $14 \%$ of the total sample in foundation training and the remaining $86 \%$ in post foundation training. A total of 1273 individuals provided at least one response to a choice scenario within the DCE. We excluded 28 respondents because of a high rate of missing values on the series of choices ( 6 or more choices out of the 9 presented), leaving the total number of observations (choices) available for analysis as 11,177 . This further reduces to 1187 individual respondents for the sub-group analysis who provide a total of 10,657 observations.

\section{Priorities}

The results in Table 2 report the main effects of the training position characteristics on respondents' choice of position. The results indicate that all coefficients are statistically significant at the $5 \%$ level and that all attributes influenced the training position choices. The estimated preferences were in line with our a priori assumptions regarding effects of improvements in characteristics of training positions. Positive estimates for the highest level of the different attributes supported the theoretical validity of our DCE results.

\section{Table 2 about here}

The value that the average respondent places on the characteristic levels is calculated using estimated willingness to pay or to accept compensation for movements between levels (Table 2, column 5). The largest single compensation that would be required is for a move from a training position which has good working conditions to one which has poor working conditions. To accept this detrimental move the average respondent would require compensation equivalent to at least $49.8 \%$ above average potential earnings (=38.6 - (-11.2)) within their specialty of choice. The move from good working conditions to excellent working conditions is equivalent to $16.1 \%$ above average potential earnings $(=-27.3 \%-(-11.2 \%))$ within their specialty of choice, indicating that the value trainees place on moving between poor and good conditions is significantly more than moving from good to excellent working conditions. 
The results also indicate that trainee doctors highly value the training location - moving from a not so desirable to a desirable geographical location is estimated to be equivalent to potential earnings $30.8 \%$ above the average within their specialty of choice. Similarly, a move from a training location with only limited opportunities for a partner/spouse to one that has good opportunities is equivalent to $38.5 \%$ above average potential earnings within their specialty of choice.

If required to move from a training position that had a good clinical reputation to one which had an indifferent reputation, the average postgraduate medical trainee would need to be compensated by potential earnings that were $25.8 \%$ above the average within their specialty of choice. However, the average postgraduate medical trainee values the move from a training position with a good reputation to that which had an excellent reputation as equivalent to $8.1 \%$ above the average within their specialty.

The smallest single compensation that would be required comes from moving from a training position in a hospital that the respondent is quite familiar with to a training position in a hospital that they are unfamiliar with. Such a move would require a small but still significant compensation of $4.2 \%$ above the average earnings within their specialty choice.

A comparison of the WTP/A values of extreme moves from best to worst levels of all the training position characteristics indicate that working conditions is twice as influential on trainees' choices than location, opportunities for partner and clinical reputation, and four times more influential than familiarity. The working condition attribute is a key driver of trainee doctors' medical career decisions.

\section{Subgroup analysis - Effect of personal circumstances}

Table 3 reports the number of respondents by each of our sub-groups of interest. Once the variable selection procedure has been used, seven interaction effects with significance at least at the $10 \%$ level remain in the final model (Table 4).

\section{Tables 3 and 4 about here}

Four of the statistically significant interaction terms are related to the opportunities for partner/spouse characteristic. From the main effect in Table 4 the magnitude of the overall 
preference for having good opportunities for partner/spouse is +0.3791 . The interaction effect with gender indicates that male trainees valued having good opportunities for their partner/spouse less than female trainees (the preference magnitude for male trainees is $+0.3423=0.3791+(-0.0368)$ ). $\mathrm{A}$ similar interaction effect is found for age (trainees who are older than 30 years valued good opportunities for their partner/spouse less than trainees younger than 30 years) and nationality (trainees who are not British citizens valued good opportunities less than British citizens). As one would expect, the interaction effect between relationship status and opportunities for partner/spouse is especially large $(-0.1235)$ with single trainees valuing good opportunities for a partner/spouse less than trainees in a long term relationship). The age of medical trainees also impacts on the value respondents place on the familiarity of training position where trainees who are older than 30 years value a very familiar position less than trainees younger than 30 . Only one interaction relating to stage of training is statistically significant in the model with trainees at core/specialty training years 1 or 2 but not on a run-through programme place less negative value on an unfamiliar training location than those in any other stage of training.

This analysis of interaction effects seems to indicate a high degree of homogeneity in medical trainees' preferences for characteristics of training positions with only seven significant interaction effects remaining in the final specification of the choice model out of 90 possible. Indeed some individual characteristics, such as the location of the current deanery and desire to change deanery, have been completely removed from the final model with no evidence that these subgroups differ in terms of how they value training position characteristics. 


\section{Discussion}

Unlike the majority of research on this topic, this study did not look at medical careers decision making in terms of specialty choice (e.g., a preference for surgery or general practice). Rather, our focus was on generic "push-pull" factors (36). Our aim was to identify the relative importance of factors that a unit/ department/healthcare organisation might have some control over (e.g., working conditions) versus those that are beyond their control (e.g., not being located near a trainee's family or friends), no matter the specialty. We found that doctors in training prefer positions with good working conditions, good opportunities for their partner and one which is desirable in terms of geographical location, which encompasses proximity to family and friends. The compensation (interpreted as the amount that a trainee would need to be paid to take on such a position) required to move from a position perceived as good in terms of these characteristics varied from just over $30 \%$ to nearly $50 \%$ of average earnings within the specialty.

The factor which was of most importance to respondents was good working conditions. Working conditions may be analogous, at least to some extent, to good "learning environment" (LE), previously shown to be influential on career choice $(44,45)$. More broadly, numerous studies have shown significant associations between learners' perceptions of the clinical LE and optimal learning (46-48) including the development of professionalism $(47)$, and achievement $(46,48)$. The LE also has a profound impact on burnout (49). Given this wider literature, it is scarcely surprising that good working conditions are so important to doctors to training, further emphasising the need to ensure quality in training environments (e.g., 50). Interestingly, even with national selection (as is the case for medical training in the UK), anecdotal evidence indicates that medical students and trainees draw on their own and friends' experiences, and make many informal enquiries via their own networks and social media, about what it is like to "be a trainee" in hospital/unit/practice x or y. If they do not hear good reports, they rank these places low in their training post applications, and hence "vote with their feet". Is the opposite true? Can a hospital/unit/practice in an undesirable location increase its attractiveness to trainees (and those in fully-trained posts) by investing in highquality working and learning environments? Further research is required.

This is the first study to explore what is important to today's UK trainees and the first to identify the relative importance, or value, of a range of factors in their careers decision making. The use of a Discrete Choice Experiment allows us to estimate monetary values in relation to changing levels with any one particular training place characteristic and also between characteristics. The DCE attributes 
were defined through a best-practice process, which allowed us to tease out more precise details of what is important to today's doctors in training than has previously been identified. However, although every care was taken in this process, we cannot be certain that the factors entered into the DCE were exclusive. An important strength of this study is that it surveyed medical trainees in all stages of training including the early years, when, in the current UK system, they have experience of many specialties but yet may either still have key careers decisions to make and may decide not to continue training in a particular specialty. Of course, this could also be seen as a weakness because we did not ask about actual specialty preference so we could not compare if compensation values for popular/competitive versus unpopular specialties varied (for example, for a coveted, highly competitive training post, does a trainee re-value certain factors?).

A DCE does not measure actual behaviour - individuals are asked to consider a hypothetical scenario - so we do not know if stated preferences and actual behaviour diverge. However, it would be very difficult to examine this in any robust way given the number of potentially confounding variables likely in any one individual's progression through medical education and training (e.g., not passing the required postgraduate examinations, a change in domestic circumstances). However, one benefit of a DCE is that it provides preferences and information that are otherwise impossible to reveal when actual choice behaviour is restricted in some way (51).

Our sample was very heterogeneous, from newly qualified doctors to those nearing the end of training, yet we found few differences related to stage of training - only that those earlier in training place less negative value on unfamiliar workplaces. This may reflect the norms of early training, when rotations are frequent, and/or people have fewer domestic commitments to manage (e.g., employment for a partner, children's schooling: 52), making moving locality relatively straightforward. Note that our choice of age 30 years as a cut off for analysis was based on statistical decisions rather than related to, for example, typical age at making a particular careers or indeed domestic decision in medicine.

An online survey has methodological limitations, but was the only practical way to reach a large number of trainees spread across two countries and more than 100 different localities, including tertiary centres, district general hospitals and general practices, urban and rural areas. The number of responses was sufficiently high to allow for appropriate statistical analysis although we recognise that with an $8 \%$ response rate there is a possibility of response rate bias. 
We acknowledge that this study took place in one country, with, broadly speaking, one healthcare service and training environment. Given this, we would not assume that the findings of this study are generalizable across different systems/countries, or even to different parts of the UK. However, we do believe that our finding that doctors in training differentially value different training characteristics is likely to hold generally but this, of course, requires further study.

\section{Implications for policy, practice and research}

This study opens up a number of potentially fruitful areas for future research. Using mixed-methods designs and sampling groups of medical students and doctors in training at pivotal career decision making times (e.g., when applying for the Foundation Programme in the final year of medical school, when applying for Core or Specialty training in Foundation Year 2 would enable comparisons between stated preferences and actual career-related behaviour, and allow longitudinal follow-up of individuals to see how preferences change with time. Comparing across specialties, particularly across popular and less popular specialties, would give insight into whether the value placed on certain factors varies across trainee groups. It would also be worthwhile to investigate if efforts to improve "undesirable" hospitals/units/practices produces benefits in terms of increasing the attractiveness of these places to trainees.

Hospitals and other healthcare institutions cannot change where they are located. However, we would argue that they can make changes to working conditions, the factor which was of greatest importance to our respondents. Our findings suggest there is a larger return to improving conditions from poor to good than from good to excellent, which may help in terms of focusing investment and improvement. Second, acknowledge that trainee locality of origin is a factor when assigning training posts. This could link with the widening access agenda in medical education $(53,54)$ in terms of focusing outreach activities to recruit medical students from areas of the country which are known to struggle to fill posts. This may also have benefit of achieving a closer alignment of the medical workforce to the community it serves. Third, link training places for medical couples and offer career-related counselling and support to accompanying non-medical partners (a benefit often provided by organisations in other sectors).

Central to change however, is that the current difficulties distributing trainees across specialty and region are likely to continue unless we adopt more reliable and contemporary approaches to 
workforce planning (55), solutions which consider the needs of both the providers and the recipients of healthcare. 


\section{Contributions}

$\mathrm{JC}$ and PJ had the original idea for the DCE, which was developed in collaboration with DS and VW.

JC prepared the ethics application. JC lead on the literature review. DS, JC, PJ, NK and VW developed the DCE content. DS managed the analysis, which was carried out by NK. JC, PJ, VW and NK contributed throughout the analysis of the DCE. JC drafted the paper with DS, NK and VW drafting the DCE methods and analysis sections. All authors contributed to the final paper. The study is guaranteed by the University of Aberdeen.

\section{Ethical permission}

Ethical permission was granted for this study from the University of Aberdeen College of Life Sciences and Medicine Ethics Research Board (CERB reference 2013/4/903, approval granted $5^{\text {th }}$ June 2013).

\section{Funding}

Our thanks go to NHS Education for Scotland for funding this programme of work.

\section{Acknowledgements}

Our thanks first to the following colleagues (in alphabetic order) for their support: Professor Phillip Cachia, East of Scotland Deanery; Professor Jacky Hayden, CBE, North Western Deanery; Professor Stewart Irvine, NHS Education for Scotland; Dr Namita Kumar, Health Education North East England; Professor Alastair McLellan, West of Scotland Deanery; Professor Gillian Needham, North of Scotland Deanery; Professor William Reid, South East of Scotland Deanery; and Ms Jayne Scott, NHS Education for Scotland. Our thanks also go to the START Core Group-Professor Alastair McLellan, Professor Rowan Parks, Dr Ronald MacVicar and Ms Anne Dickson. We also thank Professor Charlotte Rees and Dr Karen Mattick for their feedback on the project proposal, the project report and the qualitative survey which informed the DCE. Our thanks to John Lemon for his sterling work and endless patience when developing and managing the online surveys. Finally, we would like to thank all the doctors in training who participated in the DCE.

\section{Competing Interests}

JC, PJ, DS, VW and NK have support from the University of Aberdeen and NHS Education Scotland (NES) for the submitted work; (2) JC, DS, VW and NK have no relationships with NES or HEE while PJ is an associate Postgraduate Dean (3) their spouses, partners, or children have no financial relationships that may be relevant to the submitted work; and (4) JC, PJ, DS, VW and NK have no non-financial interests that may be relevant to the submitted work. 


\section{References}

1. BMA News. HEE figures. General practice faces serious threat to recruitment. 13 June 2014. http://bma.org.uk/news-views-analysis/news/2014/june/general-practice-faces-seriousthreat-to-recruitment.

2. Carr A, Marvell J, Collins J. Applying to specialty training: considering the competition. BMJ Careers 8 Nov 2013. http://careers.bmj.com/careers/advice/view-article.html?id=20015362

3. Health Education England. Investing in people for health and healthcare. Proposed education and training commissions for 2014/15-workforce plan for England (December 2013). http://hee.nhs.uk/wp-content/uploads/sites/321/2013/12/Workforce-planinteractive1.pdf

4. College of Emergency Medicine (CEM) 2012. Emergency Medicine Taskforce Interim Report Executive Summary, CEM, London.

5. Hughes G. Emergency Medicine Taskforce; An Interim Report. Emergency Medicine Journal, 2013; 30: 348 doi:10.1136/emermed-2012-202260.

6. Coulston C, Vollmer-Conna U, Malhi G. Female medical students: Who might make the cut? Psychiatry Research 2012; 200: 457-463.

7. Pedersen LT, Bak NH, Dissing AS, Petersson BH. Gender bias in specialty preferences among Danish medical students: a cross-sectional study. Dan Med Bul 2011; 58: A4304.

8. van der Horst K, Siegrist M, Orlow P, Giger M. Residents' reasons for specialty choice: influence of gender, time, patient and career. Med Educ 2010;44:595-602.

9. Taylor KS, Lambert TW, Goldacre MJ: Career progression and destinations, comparing men and women in the NHS: Postal questionnaire surveys. BMJ 2009, 338:b1735.

10. Dorsey ER, Jarjouram D, Rutecki GW. The influence of controllable lifestyle and sex on the specialty choices of graduating US medical students, 1996-2003. Acad Med 2005;80:791-6.

11. Dorsey ER, Jarjoura D, Rutecki GW. Influence of controllable lifestyle on recent trends in specialty choice by US medical students. JAMA 2003;290:1173-8.

12. Newton DA, Grayson MS, Thompson LF. The variable influence of lifestyle and income on medical students' career specialty choices: data from two US medical schools, 1998-2004. Acad Med 2005;80:809-14.

13. Cleland JA, Johnston PW, Michael A, Khan N, Scott NW. A survey of factors influencing career preference in new-entrant and exiting medical students from four UK medical schools. BMC Medical Education 2014, 14:151. 
14. Satiani B, Williams TE, Ellison EC: The impact of employment of part-time surgeons on the expected surgeon shortage. J Am Coll Surg 2011,213:345-351.

15. Polansky M. A Historical Perspective on Postgraduate Physician Assistant Education and the Association of Postgraduate Physician Assistant Programs. Journal of Physician Assistant Education 2007; 18 (3): 100-108.

16. Tonna AP, Stewart D, West B, McCaig D. Pharmacist prescribing in the UK - a literature review of current practice and research. Journal of Clinical Pharmacy and Therapeutics 2007; 32 (6): 545-556.

17. McManus IC, Lefford F, Furnham AF, Shahidi S, Pincus T. Career preference and personality differences in medical school applicants. Psychol Health Med 1996;1:235-48.

18. Soethout MBM, Heymans MW, ten Cate OTJ. Career preference and medical students' biographical characteristics and academic achievement. Med Teach 2008;30:15-30.

19. Maiorova T, Stevens F, Scherpbier A, van der Zee J. The impact of clerkships on students' specialty preferences: what do undergraduates learn for their profession? Med Educ 2008;42:554-62.

20. Deutsch T, Hönigschmid P, Frese T, Sandholzer H. Early community-based family practice elective positively influences medical students' career considerations - a Pre-postcomparison. BMC Family Practice 2013, 14:24.

21. Akhund S, Shaikh ZA, Kolachi H B. Career related choices of medical students from an International Medical College of Karachi, Pakistan. JLUMHS 2012; 11: 03.

22. Svirko E, Lambert T, Brand L, Goldacre MJ. Career choices of the United Kingdom medical graduates of 2005, 2008 and 2009: questionnaire surveys. Med Teach. 2013; 35: 365-75.

23. Kiker BF, Zeh M. Relative income expectations, expected malpractice premium costs, and other determinants of physician specialty choice. J Health Soc Behav 1998;39:152-67.

24. Goldacre MJ, Turner G, Lambert TW. Variation by medical school in career choices of UK graduates of 1999 and 2000. Med Educ 2004;38:249-58.

25. Goldacre MJ, Turner G, Lambert TW. Variation by medical school in career choices of UK graduates of 1999 and 2000. Med Educ 2004;38:249-58.

26. Boyle E, Healy D, Hill ADK, O'Connell PR, Kerin M, McHugh S, Coyle P, Kelly J, Walsh SR, Coeffey JC. Career choices of today's medical students: where does surgery rank? Ir J Med Sci, 2013; 182:337-343.

27. Gibis B, Heinz A, Jacob R, Müller CH: The career expectations of medical students: findings of a nationwide survey in Germany. Dtsch Arztebl Int 2012; 109(18): 327-32. 
28. Zinn WM, Sullivan AM, Zotov N, Peters AS, Connelly MT, Singer JD, Singer J, Block S. The effect of medical education on primary care orientation: results of two national surveys of students' and residents' perspectives. Acad Med 2001;76:355-65.

29. Kolstad J. How to make rural jobs more attractive to health workers. Findings from a discrete choice experiment in Tanzania. Health Economics 2010; 20(2): 196-211.

30. Lancaster K. A new approach to consumer theory. J Polit Econ 1966;74(2): 132-157.

31. Visholm A, Grosen L, Nom MT, Jensen RL. Interdisciplinary research is key to solving society's problems. Copenhagen: DEA.

http://dea.nu/sites/dea.nu/files/Resume_Interdisciplinary\%20Research.pdf (Accessed 7th August 2014).

32. Mandeville KL, Lagarde M, Hanson K. The use of discrete choice experiments to inform health workforce policy: a systematic review. BMC Health Services Research 2014; 14:367 http://www.biomedcentral.com/1472-6963/14/367

33. Ubach C, Scott A, French F, Awramenko M, Needham G. What do hospital consultants value about their jobs? A discrete choice experiment. BMJ 2003; 326: 1432.

34. Wordsworth S, Skatun D, Scott A, French F. Preferences for general practice jobs: a survey of principals and sessional GPs. The British Journal of General Practice 2005; 54: 740-746.

35. Sivey $P$, Scott A, Witt J, Joye C, Humphreys J. Junior doctors' preferences for specialty choice. Journal of Health Economics 2012, 31: 813- 823.

36. Castles, S. and Miller, M.J. (2009) The Age of Migration: International Population Movements in the Modern World, 4th ed. New York: Guilford.

37. Ryan M, Gerard K, Amaya-Amaya M. 2008. Using Discrete Choice Experiments to Value Health and Health Care, vol. 11. Springer: Dordrecht, The Netherlands.

38. Klojgaard M, Bech M, Sogaard R. Designing a stated choice experiment: The value of a qualitative process. Journal of Choice Modelling 2012, 5: 1-18.

39. Ritchie, J. and Spencer, L. (1994) 'Qualitative Data Analysis for Applied Policy Research', in A. Bryman and R. Burgess (eds) Analyzing Qualitative Data, pp.173-94. London: Sage.

40. Cleland JA, Johnston P, Mattick K, Rees C, Skatun D, Watson V. Understanding push-pull factors in medical careers decision making. A final project report submitted to NHS Education for Scotland November 2013.

41. Reed Johnson F, Lancsar E, Marshall D, Kilambi V, Muhklbacher A, Regier DA, Bresnahan BW, Kanninen B, Bridges JFP. Constructing Experimental Designs for Discrete-Choice Experiments: Report of the ISPOR Conjoint Analysis Experimental Design Good Research Practices Task Force. Value in Health Volume 2013; 16: 3-13. 
42. Louvierea JJ, Flynna TN, Carsonb RT. Discrete Choice Experiments Are Not Conjoint Analysis. Journal of Choice Modelling 2010; 3: 57-72.

43. Tibshirani, R. (2011), Regression shrinkage and selection via the lasso: a retrospective. Journal of the Royal Statistical Society: Series B (Statistical Methodology), 73: 273-282. doi: 10.1111/j.1467-9868.2011.00771.x

44. Hodkinson $\mathrm{P}$, Hodkinson $\mathrm{H}$. Individuals, communities of practice and policy context: school teachers' learning in their workplace. Studies in Continuing Education 2003;25 (1):3-21.

45. Beckett D, Hager P. Life, Work and Learning: Practice in Postmodernity. Routledge International Studies in the Philosophy of Education 14. London/New York: Routledge 2002.

46. Genn JM. AMEE Medication Education Guide No. 23 (Part 2): curriculum, environment, climate, quality and change in medical education - a unifying perspective. Medical Teacher 2001; 23:445-54.

47. Gracey $C F$, Haidet $P$, Branch WT et al. Precepting humanism: strategies for fostering the human dimensions of care in ambulatory settings. Academic Medicine 2005; 80: 21-8.

48. Lucas CA, Benedek D, Pangaro L. Learning climate and students' achievement in a medicine clerkship. Academic Medicine 1993; 68: 811-2.

49. Dyrbye LN, Thomas, MR, Harper W, et al. The learning environment and medical student burnout: a multicentre study. Medical Education 2009; 43: 274-282.

50. Greenaway, D. (20th October 2013) The Shape of Training Review. www.shapeoftraining.co.uk

51. Hanley, N. \& Spach, C. L. 1993, Cost-Benefit Analysis and the Environment Edward Elgar Publishing Company, England.

52. Goldacre, Michael J., Jean M. Davidson, and Trevor W. Lambert. "Doctors' age at domestic partnership and parenthood: cohort studies." Journal of the Royal Society of Medicine 105.9 (2012): 390-399).

53. Medical Schools Council (2014). Selecting for Excellence Final Report http://www.medschools.ac.uk/SiteCollectionDocuments/Selecting-for-Excellence-FinalReport.pdf

54. Cleland JA, Kelly N, Moffat M, Nicholson S. Taking context seriously: explaining widening access policy enactments in UK medical schools. Medical Education 2015, 49: 25-35.

55. Gorman D. Developing Health Care Workforces for Uncertain Futures. Academic Medicine 2015, 90: 00-00 (first published online) http://www.hhrrhs.ca/images/stories/Developing Health Care Workforces for Uncertain.98870.pdf 
Table 1: Characteristics of training positions and the range of possible levels presented within the choice scenarios

\begin{tabular}{|l|l|l|}
\hline Characteristics & Description given to respondents & Possible levels \\
\hline $\begin{array}{l}\text { Familiarity with } \\
\text { hospital/unit }\end{array}$ & $\begin{array}{l}\text { This refers to how familiar you are with the } \\
\text { hospital or unit, whether you have rotated } \\
\text { around it previously or have other } \\
\text { knowledge of it }\end{array}$ & $\begin{array}{l}\text { Unfamiliar } \\
\text { Quite familiar } \\
\text { Very familiar }\end{array}$ \\
\hline Geographical location & $\begin{array}{l}\text { This refers the geographical location of the } \\
\text { training position including the amenities on } \\
\text { offer and the proximity to your } \\
\text { family/friends }\end{array}$ & $\begin{array}{l}\text { Desirable } \\
\text { Not so desirable }\end{array}$ \\
\hline $\begin{array}{l}\text { Opportunities for } \\
\text { partner/spouse }\end{array}$ & $\begin{array}{l}\text { How much does the location offer } \\
\text { employment/training opportunities for } \\
\text { your partner/spouse (if you have one) }\end{array}$ & $\begin{array}{l}\text { Limited opportunities } \\
\text { Good opportunities }\end{array}$ \\
\hline Potential earnings & $\begin{array}{l}\text { This refers to how your potential earnings } \\
\text { compare against average career earnings in } \\
\text { your chosen specialty after completing } \\
\text { training }\end{array}$ & $\begin{array}{l}\text { Average earnings } \\
5 \% \text { above average } \\
10 \% \text { above average } \\
\text { 20\% above average }\end{array}$ \\
\hline Clinical/academic reputation & $\begin{array}{l}\text { This refers to the prestige/status } \\
\text { associated with the } \\
\text { Hospital/Unit/Programme }\end{array}$ & $\begin{array}{l}\text { Indifferent reputation } \\
\text { Good reputation } \\
\text { Excellent reputation }\end{array}$ \\
\hline Working conditions & $\begin{array}{l}\text { This refers to working conditions, such as } \\
\text { rotas, amount of on-call, time off and/or } \\
\text { staffing levels etc. }\end{array}$ & $\begin{array}{l}\text { Poor } \\
\text { Good } \\
\text { Excellent }\end{array}$ \\
\hline
\end{tabular}


Figure 1: DCE instructions and example of choice scenario

This section invites you to consider alternative placements/oportunities for your next stage of career. Imagine you are looking for your next position and have been offered two alternatives. The two positions only differ according to the characteristics outlined below. All other unmentioned characterisitcs are the same.

Please take a moment to read through these characteristics outlined below.

You may not like either position but we would like you to state which you think is better!

There are a series of 9 choices.

Choice 1 of 9: Which position would you prefer?

Geographical Location

Familiarity with hospital/unit

Opportunities for partner/spouse

Potential earnings

Working conditions

Clinical/academic reputation

Please tick one box

\begin{tabular}{|c|}
\hline Position "A" \\
Not so desirable location \\
Unfamiliar \\
Good opportunities \\
Average earnings \\
Poor conditions \\
Indifferent reputation \\
\hline
\end{tabular}

?

\section{Position "B"}

Desirable location

Quite familiar

Limited opportunities

$20 \%$ above average

Excellent conditions

Good reputation 
Table 2. Conditional Logit model of the main effect estimates with the and resulting willingness-to-pay/accept estimates as \%'age of earnings (Ratio of estimated coefficient of attribute of interest with earnings) coefficient) Regression results Monetary Value

\begin{tabular}{|c|c|c|c|c|c|c|}
\hline & Beta & $\mathrm{CRSE}^{+}$ & P-val. & WTP & & $95 \% \mathrm{Cl}^{++}$ \\
\hline Constant & 0.2770 & 0.0367 & 0.0001 & & & \\
\hline Location: Not so desirable & -0.3913 & - & - & 15.4 & 10.2 & 22.2 \\
\hline Location: Desirable & 0.3913 & 0.0158 & 0.0001 & -15.4 & -22.2 & -10.2 \\
\hline Partner opportunities: Limited & -0.4908 & - & - & 19.2 & 13.1 & 28.5 \\
\hline Partner opportunities: Good & 0.4908 & 0.0143 & 0.0001 & -19.2 & -28.5 & -13.1 \\
\hline Familiarity: Unfamiliar & -0.1581 & 0.0227 & 0.0001 & 6.2 & 2.7 & 10.4 \\
\hline Familiarity: Quite & -0.0477 & - & - & 1.9 & -1.5 & 5.7 \\
\hline Familiarity: Very & 0.2058 & 0.0225 & 0.0001 & -8.1 & -13.6 & -3.9 \\
\hline Working conditions: Poor & -0.9867 & 0.0243 & 0.0001 & 38.6 & 28.1 & 54.0 \\
\hline Working conditions: Good & 0.2894 & - & - & -11.2 & -16.5 & -7.4 \\
\hline Working conditions: Excellent & 0.6973 & 0.0244 & 0.0001 & -27.3 & -39.1 & -19.3 \\
\hline Reputation: Indifferent & -0.4696 & 0.0233 & 0.0001 & 18.4 & 12.4 & 26.3 \\
\hline Reputation: Good & 0.1397 & - & - & -5.5 & -9.8 & -2.3 \\
\hline Reputation: Excellent & 0.3299 & 0.0204 & 0.0001 & -12.9 & -18.9 & -8.9 \\
\hline Potential earning (in \%) & 0.0262 & 0.0023 & 0.0001 & & & \\
\hline
\end{tabular}

Log-Likelihood $=-5,013.4$

Observations $=11,177$ (from 1,245 respondents)

\footnotetext{
${ }^{+}$Cluster-Robust Standard Errors

${ }^{+\dagger}$ Bootstrapping procedure: 1,000 replications of subsample including 300 respondents
} 
Table 3. Descriptive analysis summary of the individuals' characteristics (subgroup characteristics analysis)

\begin{tabular}{|c|c|c|}
\hline Characteristic & $\mathbf{N}$ & $\%$ \\
\hline \multicolumn{3}{|l|}{ Location of the deanery } \\
\hline Scotland & 688 & $58.0 \%$ \\
\hline England & 499 & $42.0 \%$ \\
\hline \multicolumn{3}{|l|}{ Age } \\
\hline Less than 30 years old & 690 & $58.1 \%$ \\
\hline More than 30 years old & 497 & $41.9 \%$ \\
\hline \multicolumn{3}{|l|}{ Gender } \\
\hline Female & 745 & $62.8 \%$ \\
\hline Male & 442 & $37.2 \%$ \\
\hline \multicolumn{3}{|l|}{ Nationality } \\
\hline U.K. & 944 & $79.5 \%$ \\
\hline Overseas & 243 & $20.5 \%$ \\
\hline \multicolumn{3}{|l|}{ Marital status } \\
\hline Single & 919 & $77.4 \%$ \\
\hline Long-term relationship & 268 & $22.6 \%$ \\
\hline \multicolumn{3}{|l|}{ Stage of training } \\
\hline ST3on (higher specialty training) & 597 & $50.3 \%$ \\
\hline CTST/N (core/ST1 or2- not run-through) & 195 & $16.4 \%$ \\
\hline CTST $/ Y$ (core/St1 or 2 run-though path) & 224 & $18.9 \%$ \\
\hline FY (Foundation Years) & 171 & $14.4 \%$ \\
\hline
\end{tabular}


Table 4. Conditional Logit model to identify significant of the sub-group interaction effects on choice of training location

\begin{tabular}{|c|c|c|c|}
\hline Parameter & Beta & CRSE* & P-val. \\
\hline \multicolumn{4}{|l|}{ 1. Main effects } \\
\hline Constant & 0.2770 & 0.0351 & 0.1 \\
\hline Location: Not so desirable & -0.3551 & - & \\
\hline Location: Desirable & 0.3551 & 0.0229 & 0.0001 \\
\hline Partner opportunities: Limited & -0.3791 & - & \\
\hline Partner opportunities: Good & 0.3791 & 0.0257 & 0.0001 \\
\hline Familiarity: Unfamiliar & -0.4555 & 0.0279 & 0.0001 \\
\hline Familiarity: Quite & 0.1203 & - & \\
\hline Familiarity: Very & 0.3352 & 0.0193 & 0.0001 \\
\hline Working conditions: Poor & -1.0079 & 0.0318 & 0.0001 \\
\hline Working conditions: Good & 0.3000 & - & \\
\hline Working conditions: Excellent & 0.7079 & 0.0278 & 0.0001 \\
\hline Reputation: Indifferent & -0.1515 & 0.0249 & 0.0001 \\
\hline Reputation: Good & -0.0531 & - & \\
\hline Reputation: Excellent & 0.2046 & 0.0273 & 0.0001 \\
\hline Potential earning (in \%) & 0.0263 & 0.0022 & 0.0001 \\
\hline \multicolumn{4}{|l|}{ 2. Interaction effects } \\
\hline Location (Desirable) $x$ Older than 30 years & -0.0471 & 0.0175 & 0.0072 \\
\hline Location (Desirable) x Non British nationality & -0.0666 & 0.0206 & 0.0012 \\
\hline Partner opportunities (Good) x Older than 30 years & -0.0602 & 0.0185 & 0.0012 \\
\hline Partner opportunities (Good) x Male & -0.0368 & 0.0181 & 0.0416 \\
\hline Partner opportunities (Good) x Non British nationality & -0.0733 & 0.0229 & 0.0014 \\
\hline Partner opportunities (Good) $\times$ Single & -0.1235 & 0.0203 & 0.0001 \\
\hline Familiarity (Unfamiliar) x CTST/N & 0.0492 & 0.0274 & 0.0729 \\
\hline Familiarity (Very) $x$ Older than 30 years & -0.0233 & 0.0153 & 0.1269 \\
\hline Reputation (Indifferent) x Older than 30 years & 0.0241 & 0.0166 & 0.1473 \\
\hline \multicolumn{4}{|l|}{ Log-Likelihood = $-4,684.6$} \\
\hline Observations = 10,657 (from 1,187 respondents) & & & \\
\hline
\end{tabular}

*Cluster-Robust Standard Errors 